\title{
Interaction of titanium with smectite within the scope of a spent fuel repository: A spectroscopic approach
}

\author{
DANIEL GROLIMUND ${ }^{1, *}$, PAUL WERSIN ${ }^{2}$, JOCELYNE BRENDLÉ ${ }^{3}$, \\ JOFFREY HUVE ${ }^{3}$, LEENA KIVIRANTA ${ }^{4}$ AND MARGIT SNELLMAN ${ }^{5}$ \\ ${ }^{1}$ Paul Scherrer Institute, CH-5232 Villigen PSI, Switzerland \\ ${ }^{2}$ University of Bern, CH-3012 Bern, Switzerland \\ ${ }^{3}$ Université de Haute-Alsace, F-68093 Mulhouse, France \\ ${ }^{4}$ B + Tech Oy, FIN-00420 Helsinki, Finland \\ ${ }^{5}$ Saanio \& Riekkola Oy, FIN-00420 Helsinki, Finland
}

(Received 31 May 2015; revised 13 January 2016; Guest editor: Reiner Dohrmann)

\begin{abstract}
The Swedish and Finnish nuclear waste repository design, KBS-3H, foresees horizontal emplacement of copper canisters-bentonite modules surrounded by a titanium shell. The interaction of titanium with bentonite was studied here using a combination of wet chemistry and a spectroscopic approach to evaluate the potential impact of Ti corrosion on the clay. For natural analogue clays with high Ti contents, spectroscopic investigations showed that titanium occurs as crystalline $\mathrm{TiO}_{2}$. In contrast, the Ti in the MX-80 bentonite occurs in the clay structure, presumably in the octahedral sheet. Hydrothermal tests conducted at $200^{\circ} \mathrm{C}$ using synthetic montmorillonite showed little if any change in the montmorillonite structure at near-neutral and acidic conditions. Under alkaline conditions, limited alteration was observed, including the formation of trioctahedral clay minerals and zeolite. These changes, however, occurred independently of the addition of Ti. In the batch tests conducted at $80^{\circ} \mathrm{C}, \mathrm{Ti}$ did not occur as separate $\mathrm{TiO}_{2}$ particles. The comparison of experimental data with spectroscopic simulations provides sound evidence that $\mathrm{Ti}$ was incorporated in a neoformed phyllosilicate structure.
\end{abstract}

KEYWORDS: titanium, smectite, corrosion, interaction, spectroscopy.

Most concepts of geological repositories for highlevel and spent-fuel radioactive waste include swelling clay materials used as a safety barrier. For example, in the Swedish and Finnish repository reference design, KBS-3 V, the copper canister surrounded by compacted bentonite blocks will be emplaced in vertical deposition holes (SKB, 2011; Posiva, 2013). As an alternative, a horizontal emplacement design, termed $\mathrm{KBS}-3 \mathrm{H}$, is envisioned, whereby modules of canisterbentonite are surrounded by a perforated metal shell (termed the 'supercontainer') and emplaced in

*E-mail: daniel.grolimund@psi.ch DOI: 10.1180/claymin.2016.051.2.11 deposition drifts (Fig. 1). In the original design, carbon steel was selected as the shell material (SKB/ Posiva, 2008). Anaerobic iron corrosion releases large amounts of hydrogen in the repository environment (King, 2008). Furthermore, corroded iron species interact strongly with the bentonite clay and may, at least locally, impair the safety functions of this barrier (Wersin \& Birgersson, 2014). Because of these adverse effects, titanium rather than steel has been selected as the supercontainer shell material in the new KBS-3H design (SKB, 2012; Posiva, 2012). This metal is known to display very low corrosion rates and low mobility over a wide range of environmentally relevant conditions (Schutz, 2005; SKB, 2012; Posiva, 2012). 


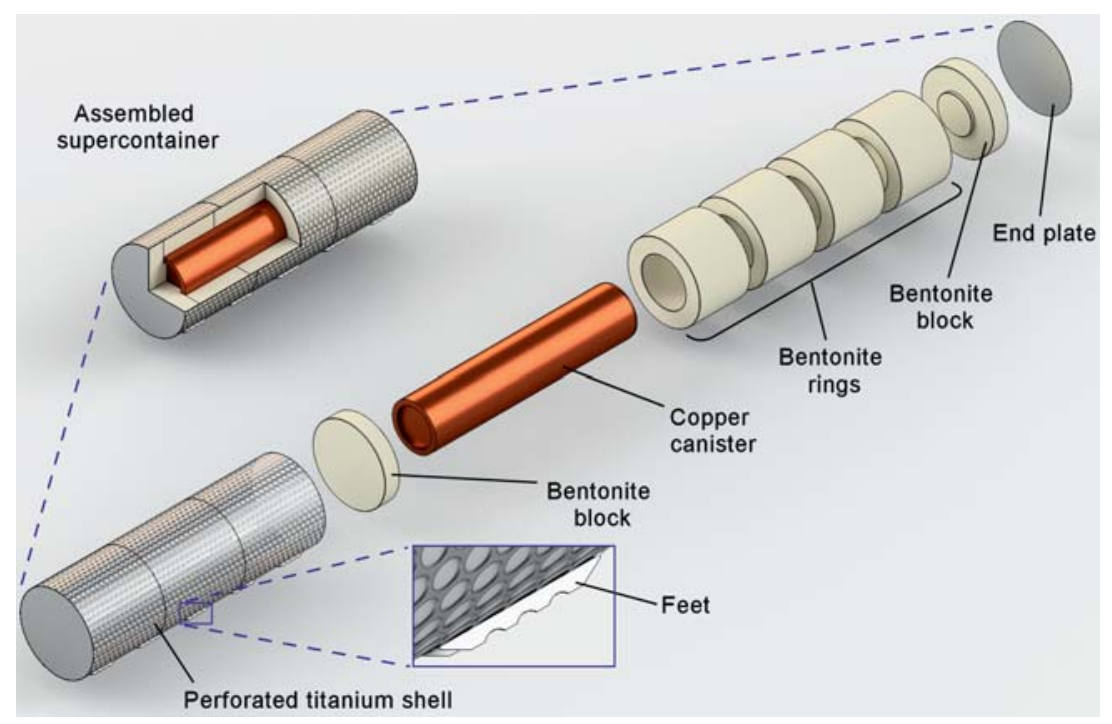

FIG. 1. Illustration of the emplaced components in the KBS-3H disposal concept (based on Posiva, 2012). Exploded assembly drawing showing a supercontainer with copper canister, bentonite buffer and perforated Ti shell.

The corrosion of $\mathrm{Ti}$ in clayey environments and interactions between titanium and clay have received relatively little attention to date. Electrochemical corrosion studies on $\mathrm{Ti}$ in bentonite suspensions have shown that an anodic Ti oxide film formed in all samples which was unstable at a higher temperature $\left(80^{\circ} \mathrm{C}\right)$ (Azumi et al., 2000; Azumi \& Seo, 2003). In samples containing carbon steel and Ti-clad carbon steel, galvanic coupling between $\mathrm{Ti}$ and $\mathrm{Fe}$ was observed, resulting in a significantly higher anodic corrosion rate at the $\mathrm{Fe}$ side, whereas at the cathodic side the $\mathrm{TiO}_{2}$ passive layer was affected. A pioneer long-term study on $\mathrm{Ti}$ corrosion in contact with compacted bentonite at $95^{\circ} \mathrm{C}$ was carried out within the corrosion programme of the Swedish Nuclear Fuel and Waste Management (SKB) organization (Mattsson \& Olefjord, 1984; Mattsson \& Olefjord, 1990; Mattsson et al., 1990). The main findings from that work were: (1) that the overall corrosion rates were very low $(\leq 1 \mathrm{~nm} / \mathrm{a})$ and similar in simulated groundwater solution and in compacted bentonite; (2) the film growth was independent of the ionic strength and the composition of the Ti alloy and could be described by an empirical logarithmic rate law; and (3) the only $\mathrm{Ti}$ species identified in the clay matrix was $\mathrm{TiO}_{2}$, although this aspect was not studied in detail.

Nevertheless, the reactivity of Ti with clay materials is of fundamental importance in the context of assessing the overall performance of the barrier systems. In particular, potentially adverse effects of $\mathrm{Ti}$ and its corrosion products need to be assessed in detail. Of fundamental importance is the chemical nature of the species formed after the Ti corrosion products have reacted with clay-barrier materials. Possible molecular interaction mechanisms of Ti with clays include: (1) sorption by cation exchange; (2) specific (inner-sphere) sorption to clay-mineral edge sites; (3) substitution of Al and Si by Ti in octahedral or tetrahedral sheets of clay minerals; and (4) precipitation of secondary phases such as $\mathrm{TiO}_{2}$, Ti-Fe oxides or Ti silicate phases. Sorption processes and the formation of nano-crystalline or amorphous ('gel-like') Ti-oxide phases may influence the retention characteristics and the swelling properties of the clay barrier. Identification of the predominant molecular interaction processes is crucial in order to assess potential impacts on the safety functions of the clay barrier. Consequently, there is need for analytical investigations capable of providing molecular-level information. There are two main obstacles to molecular-level investigations on Ti-clay interaction. First, based on the extremely low corrosion rates and low solubility of $\mathrm{Ti}^{4+}$, only small amounts of reaction products can be expected to form during experimentally accessible timescales. Second, the considerable levels of geogenic Ti present even in 'purified' natural clay samples generally mask the molecular characteristics of the $\mathrm{Ti}$ reaction products. To the best of our knowledge, no 
study has so far looked at potential mineralogical or structural changes in the clay as a result of Ti-clay interactions.

The objective of the present study, therefore, was to unravel Ti-clay interactions under conditions which are relevant to geological disposal and the KBS-3H concept. The main focus was the identification of the nature of the Ti species transferred to the clay from the corroding metal source. The following approach was adopted: first, the $\mathrm{Ti}$ species in natural clays and bentonites were identified. The characterization of $\mathrm{Ti}$ at molecular level in these natural analogues was elaborated upon by employing synchrotron-based X-ray absorption near edge structure (XANES) spectroscopy and extended X-ray absorption fine structure (EXAFS) spectroscopy complemented by high-resolution synchrotron-based X-ray powder diffraction (XRD). Then, spectroscopic and microscopic analysis of synthetic Na-montmorillonite samples exposed to corroding metallic titanium powder or foils at 80 and $200^{\circ} \mathrm{C}$ in a batch-type setup for variable periods up to 20 months was performed. In addition to $\mathrm{X}$-ray based scattering and spectroscopic techniques, Nuclear Magnetic Resonance (NMR) spectroscopy was employed to obtain molecular-level information. Synthetic 'Ti-free' montmorillonite was used rather than natural bentonite material, because of the substantial amount of pristine $\mathrm{Ti}$ in natural clays and bentonites.

\section{EXPERIMENTAL METHODS}

\section{Natural analogue materials (reference clay} samples)

Wyoming bentonite ('MX-80', provided by the American Colloid Co.) was obtained within the framework of the Alternative Buffer Material (ABM) project (Svensson et al., 2011). Both the raw material and the separated clay fraction were used for subsequent spectroscopic analysis. The clay fraction in homo-ionized $\mathrm{Na}$-form was prepared according to the purification procedure described by Karnland et al. (2006). Despite the rigorous purification procedure, the purified MX-80 also contained trace amounts of mineral impurities (quartz and cristobalite) and organic matter in addition to smectite. Titanium was essentially constant (Table 1) indicating that it was either structurally bound within montmorillonite or present as clay-sized accessory minerals.

The Rokle material was obtained within the framework of the Alternative Buffer Material (ABM) project (Svensson et al., 2011) and was used in the present study as received. The material originates from argillized volcanoclastic accumulations of Tertiary age (Konta, 1986) located in the north Bohemian volcanic area NW of Prague.

Illite 'du Puy' clay material originating from a geological clay deposit located in the region of Le Puyen-Velay (Haute-Loire, France) was provided by the Waste Management Laboratory of the Paul Scherrer Institute (Villigen, Switzerland). The illite material was conditioned by repeated re-suspension in $1 \mathrm{M} \mathrm{NaCl}$ solutions to remove soluble salts and less soluble minerals such as calcite, and to convert the clay into its homo-ionic Na-form. For storage, the conditioned clay was freeze dried after washing with Milli-Q water to remove excess electrolytes. Further details of the location of the clay-rock deposit, pre-treatment and chemical as well as mineralogical characterization can be found elsewhere (Gabis, 1958; Bradbury \& Baeyens, 2009; Glaus et al., 2010). The Ti concentration was not affected by the extensive preconditioning procedures, again indicating structurally bound $\mathrm{Ti}$ in

TABLE 1. Total geogenic Ti content of natural analogue materials.

\begin{tabular}{|c|c|c|c|}
\hline Clay Material & Ti content $\left(w t . \% \mathrm{TiO}_{2}\right.$ ) & Method and reference & $\begin{array}{l}\text { Samples used in present } \\
\text { study (wt. } \% \mathrm{TiO}_{2} \text { by XRF) }\end{array}$ \\
\hline Initial MX-80 & 0.15 & ICP-AES (Wersin et al., 2010) & 0.09 \\
\hline Purified MX-80 & 0.14 & ICP-AES (Wersin et al., 2010) & n.d. \\
\hline Illite du Puy, raw product & 0.73 & ICP-AES (Glaus et al., 2010) & n.d. \\
\hline $\begin{array}{l}\text { Illite du Puy: conditioned to } \\
\mathrm{Na}^{+} \text {-form }\end{array}$ & 0.72 & ICP-AES (Glaus et al., 2010) & 0.71 \\
\hline Rokle & 3.87 & ICP-AES (Svensson et al., 2011) & 3.88 \\
\hline OPA & $0.95 \pm 0.1$ & ICP-AES (Techer et al., 2009) & 0.76 \\
\hline
\end{tabular}


the illite or the existence of highly insoluble Ti-rich mineral phases in association with the clay particles (Glaus et al., 2010).

Opalinus Clay rock material (OPA) was obtained from the Mont-Terri underground rock laboratory (URL) in NW Switzerland (Thury \& Bossart, 1999). Research galleries were excavated into an Early Dogger Opalinus Clay Rock formation. The total clay mineral content of the rock formation varies from $40 \%$ to $80 \%$, complemented mainly by quartz, calcite, siderite, pyrite and feldspar. Details of the mineralogy and chemical characteristics can be found in Thury (2002).

The total geogenic Ti content of these four natural analogue materials was measured by energy-dispersive $\mathrm{X}$-ray fluorescence (XRF) analysis using a Spectro X-LAB 2000 spectrometer (SPECTRO Analytical Instruments). To minimize matrix effects, the clay materials were diluted with wax (Licowax C, HOECHST) prior to pellet production. The $\mathrm{Ti}$ content was calculated with the fundamental parameter method to minimize the variations in the different matrix compositions. The total $\mathrm{Ti}$ concentrations obtained and comparisons with literature values are given in Table 1.

\section{Synthesis and characterization of the synthetic montmorillonite}

The large-scale synthesis of synthetic Na-montmorillonite was performed in acid and fluoride medium according to Reinholdt et al. (2001). To obtain synthetic Na-montmorillonite with the theoretical formula $\mathrm{Na}_{0.4}\left(\mathrm{Al}_{1.6} \mathrm{Mg}_{0.4}\right) \mathrm{Si}_{4} \mathrm{O}_{10}(\mathrm{OH}, \mathrm{F})_{2}, 2760 \mathrm{~g}$ of distilled water, $43.40 \mathrm{~g}$ of a $5 \mathrm{wt} . \%$ aqueous solution of hydrofluoric acid (HF, $40 \%$; BDH), $8.95 \mathrm{~g}$ of sodium acetate $\left(\mathrm{NaCOOCH}_{3}, 99 \%\right.$; Fluka), $46.61 \mathrm{~g}$ of tetrahydrated magnesium acetate $\left[\mathrm{Mg}\left(\mathrm{COOCH}_{3}\right)_{2} \bullet 4 \mathrm{H}_{2} \mathrm{O}\right.$, $99 \%$, Fluka], $56.65 \mathrm{~g}$ of boehmite $\left(\mathrm{Al}_{2} \mathrm{O}_{3}, 77\right.$ wt.\% Pural SB1; Condea), and $130 \mathrm{~g}$ of silicon oxide $\left(\mathrm{SiO}_{2}\right.$, 99.5\%, Aerosil 130; Degussa) were mixed. The hydrogel formed was matured under stirring for $2 \mathrm{~h}$ and was then treated hydrothermally at $200^{\circ} \mathrm{C}$ for $72 \mathrm{~h}$ in a PTFE-lined steel autoclave under autogenous pressure. After cooling to room temperature the solid was recovered by filtration, washed thoroughly with distilled water and dried at $60^{\circ} \mathrm{C}$ for $12 \mathrm{~h}$. The solid obtained was then ground to a fine powder. The chemical composition, determined by XRF and ${ }^{27} \mathrm{Al}$ solid state NMR spectroscopy, was $\mathrm{Na}_{0.34}\left(\mathrm{Al}_{1.49}\right.$ $\left.\mathrm{Mg}_{0.37}\right)\left(\mathrm{Si}_{3.83} \mathrm{Al}_{0.28}\right) \mathrm{O}_{10}\left(\mathrm{OH}_{1.95} \mathrm{~F}_{0.05}\right)$.

\section{Experimental procedure for experiments at $80^{\circ} \mathrm{C}$}

A. Experimental conditions. $2 \mathrm{~g}$ of synthetic, Ti-free montmorillonite was dispersed by stirring with a magnetic mixer for at least $24 \mathrm{~h}$ in $80 \mathrm{~mL}$ of $0.01 \mathrm{M}$ $\mathrm{NaCl}$ (99.9\%, BDH Prolabo) solution. The synthetic montmorillonite suspensions were bubbled with $\mathrm{N}_{2}$ for 30 min and subsequently transferred to the glovebox. During the entire extended reaction times, the sample systems remained within the acrylic glovebox flushed with $\mathrm{N}_{2}$.

In the first of two alternative procedures, $\sim 2 \mathrm{~g}$ of coarse Ti powder (325 mesh, 99.9\% purity, American Elements) were added to the suspension. In the second alternative, $2 \mathrm{~g}$ of Ti foil ( $0.1 \mathrm{~mm}$ thick, $99.5 \%$ purity, American Elements) was used. The Ti foil was etched in $1 \mathrm{M} \mathrm{HCl}$ overnight and flushed with ethanol and deaired de-ionized water before it was added to the suspension. In addition, blank samples with no added Ti were prepared. The vessels were closed, the stoppers were tightened with Teflon tape and the sample vessels were wrapped in aluminium foil to exclude the effect of light and placed in a heater at $80^{\circ} \mathrm{C}$. The experimental settings, including $\mathrm{pH}$ and electric conductivity (measured before addition of Ti), for the samples reported here, are summarized in Table 2.

After the reaction period the samples were dismantled by removing the titanium foil or separating the coarse $\mathrm{Ti}$ powder from the clay by centrifugation (1460 rpm, $5 \mathrm{~min}$; sedimenting particles $>1 \mu \mathrm{m})$. After removal of titanium (foils or coarse powder), the supernatant clay suspensions were centrifuged for $15 \mathrm{~min}$ at $11,000 \mathrm{rpm}$, and the solution was separated from the sedimented clay. After centrifugation, a trace amount of metallic Ti was still visible in the bottom of the centrifugation tubes. Apparently, the coarse Ti

TABLE 2. Initial conditions of batch samples with synthetic Na-montmorillonite in $0.01 \mathrm{M} \mathrm{NaCl}$ at $80^{\circ} \mathrm{C}$.

\begin{tabular}{lcccc}
\hline $\begin{array}{l}\text { Sample } \\
\text { ID }\end{array}$ & $\begin{array}{c}\text { Type of Ti } \\
\text { present }(2 \mathrm{~g})\end{array}$ & $\mathrm{pH}$ & $\begin{array}{c}\mathrm{EC} \\
(\mu \mathrm{S} / \mathrm{cm})\end{array}$ & $\begin{array}{c}\text { Reaction } \\
\text { time } \\
(\text { days })\end{array}$ \\
\hline 31 & - & 7.10 & 1246 & 218 \\
32 & Foil & 7.14 & 1259 & 218 \\
33 & Foil & 7.12 & 1268 & 601 \\
34 & - & 7.08 & 1272 & 601 \\
35 & Coarse powder & 7.09 & 1268 & 219 \\
36 & Coarse powder & 7.07 & 1256 & 602 \\
& & & & \\
\hline
\end{tabular}


powder (325 mesh) used also contained a fraction of smaller $\mathrm{Ti}$ metal particles, which could not be separated completely from the synthetic montmorillonite by a single centrifugation step. Hence, the uppermost portions of the sediment were scooped off using a laboratory spoon and re-suspension and centrifugation was repeated. All sedimented fractions were washed with pure ethanol, and spectroscopic analyses were performed on the humid (residual moisture after centrifugation) sediment samples after transfer to Paul Scherrer Institute (Switzerland). The solution $\mathrm{pH}$ was measured after the separation of sedimented clay inside the glovebox and the electric conductivity (EC) of the solution was recorded in laboratory air. Solutions were filtered through a $0.2 \mu \mathrm{m}$ pore-size membrane filter, and analysed for $\mathrm{Ti}, \mathrm{Ca}, \mathrm{Mg}$, $\mathrm{K}, \mathrm{Na}, \mathrm{Al}, \mathrm{Si}$ and $\mathrm{Fe}$ with ICP-AES at the accredited laboratory of Labtium Oy.

\section{Spectroscopy of natural clay samples and batch samples reacted at $80^{\circ} \mathrm{C}$}

Synchrotron-based XANES spectroscopy and EXAFS spectroscopy were conducted at the microXAS beamline (X05LA) of the Swiss Light Source. Insertion device radiation was monochromatized using $\mathrm{Si}(111)$ crystals in fixed exit geometry. Energy calibration was carried out repeatedly using a metallic $\operatorname{Ti}(0)$ reference foil. Additional Ti reference materials included the two polymorphs of $\mathrm{TiO}_{2}$, rutile and anatase, as well as the nesosilicate titanite $\left(\mathrm{CaTiSiO}_{5}\right)$. The additional reference materials were studied in transmission after appropriate dilution in boron nitride.

According to their low Ti concentration, the natural analogue materials as well as the synthetic montmorillonite samples had to be measured in fluorescence mode. Fluorescence radiation was detected by a singleelement Si drift diode (SDD) detector (Ketek $\left.{ }^{\circledR}\right)$. To

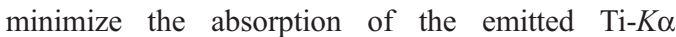
fluorescence radiation $(4.5108,4.5049 \mathrm{keV})$ by ambient air, the sample-to-detector path was purged with $\mathrm{He}$ (purging collimator nose attached to the Ketek ${ }^{\circledR}$ detector).

All samples were investigated as received without further treatment. The air-dry natural analogue clay materials and the humid synthetic clay samples were loaded in dedicated sample holders which were sealed using Kapton (DuPont ${ }^{\mathrm{TM}}$ ) polymide films.

For measurements of the reference materials and the natural analogue samples, a slit beam size of $500 \mathrm{~mm} \times 500 \mathrm{~mm}$ was employed. Due to the sporadic occurrence of metallic Ti abrasion particles within the autoclaved synthetic clay samples, these samples had to be analyzed using a microfocused beam $(\sim 5 \mu \mathrm{m}$ [horizontal] $\times 3 \mu \mathrm{m}$ [vertical] $)$. The most appropriate sample volumes free of abrasion particles were identified based on micro-XRF mapping prior to the collection of micro-XAS data from appropriate locations.

Processing of the raw EXAFS data and subsequent analysis was carried out using the DEMETER package (Ravel \& Newville, 2005). Measured EXAFS spectra were compared to simulated spectra using the FEFF8 ab initio EXAFS software package (Rehr et al., 1992; Rehr \& Albers, 2000; Rehr et al., 2009). For the EXAFS simulations related to the experimental Tisynthetic clay system, the amplitude-reduction factor and Debye-Waller factors were estimated based on the analysis of the Ti-reference compounds.

For the four natural analogue materials, synchrotronbased powder X-ray diffraction analysis was performed at the Materials Science beamline of the Swiss Light Source following their standard high-resolution powder XRD data acquisition protocol (Willmott et al., 2013).

\section{Experimental procedure for experiments at $200^{\circ} \mathrm{C}$}

A set of four sub-series with a total of nine samples was prepared. Common to all samples, $1 \mathrm{~g}$ of synthetic Na-montmorillonite was dispersed in $50 \mathrm{~mL}$ of $0.01 \mathrm{M}$ aqueous solution of sodium chloride $(\mathrm{NaCl}, 99$ wt.\%, Fluka). In order to study the influence of the $\mathrm{pH}$, the $\mathrm{pH}$ was adjusted to 2 by an aqueous solution of hydrochloric acid $(\mathrm{HCl}, 37 \mathrm{wt} \%$, Fluka), to 7 (no addition), and to 12 with an aqueous solution of sodium hydroxide ( $\mathrm{NaOH}, 99$ wt.\%, Aldrich). A first sub-series of three samples was transferred to a PTFElined stainless steel autoclave free of Ti and placed in an oven at $200^{\circ} \mathrm{C}$ for 1 month. To the remaining three sub-series, a titanium source was added. Two subseries of experiments received coarse titanium powder (325 mesh, 99.5\% purity, American Elements), while to a final sub-series, titanium foils $(0.1 \mathrm{~mm}$ thickness, 99.5\% purity, American Elements) were added. Prior to the addition of Ti powder ( $2 \mathrm{~g}$ per sample) and $\mathrm{Ti}$ foils $(2 \mathrm{~g})$ the solutions were flushed with argon for 30 min to eliminate oxygen. A second flush step was performed after adding the Ti powder or foils to the synthetic montmorillonite suspensions for $30 \mathrm{~min}$. Finally, the suspensions were transferred to autoclaves at $200^{\circ} \mathrm{C}$ for 1 month and 4 months, respectively. All samples prepared for hydrothermal treatment at $200^{\circ} \mathrm{C}$ are listed in Table 3. 
TABLE 3. Initial conditions of batch samples with synthetic Na-montmorillonite in $0.01 \mathrm{M} \mathrm{NaCl}$ at $200^{\circ} \mathrm{C}$.

\begin{tabular}{lccc}
\hline Sample ID & Type of Ti present $(2 \mathrm{~g})$ & $\mathrm{pH}$ & $\begin{array}{c}\text { Reaction time } \\
\text { (days) }\end{array}$ \\
\hline B4 & - & 7 & 30 \\
B5 & - & 12 & 30 \\
B6 & - & 2 & 30 \\
E10 & Coarse powder & 7 & 30 \\
E11 & Coarse powder & 12 & 30 \\
E12 & Coarse powder & 2 & 30 \\
E19 & Foil & 7 & 120 \\
E20 & Foil & 12 & 120 \\
E21 & Foil & 2 & 120 \\
& & & \\
\hline
\end{tabular}

At the end of the hydrothermal treatments, the autoclaves were opened and the solutions centrifuged to recover the solids which were then dried at $60^{\circ} \mathrm{C}$ for $12 \mathrm{~h}$ before analysis.

The pristine synthetic Na-montmorillonite as well as the samples treated at $200^{\circ} \mathrm{C}$ were characterized by a Panalytical MPD X'Pert Pro diffractometer with $\mathrm{Cu}$ $K \alpha$ radiation (1.5418 $\AA$ ) equipped with an $\mathrm{X}^{\prime}$ Celerator real-time multiple strip detector (active length $=2.122^{\circ}$ 20). The powder patterns were collected at $22^{\circ} \mathrm{C}$ in the range $3-70^{\circ} 2 \theta$ with a step size of $0.017^{\circ} 2 \theta$ and an integration time of $220 \mathrm{~s}$ per data point. Prior to analysis, samples were kept under a relative humidity of $80 \%$ and were pressed manually into the sample holder. Identification of the phases present was performed with the X'Pert highScore software.

The SEM images were collected using a PHILIPS XL30 microscope. A small amount of the sample was placed on a tablet with carbon adhesive tape and the tablet was then placed on an aluminium holder and coated with a gold nanolayer $(10-20 \mathrm{~nm})$.

${ }^{29} \mathrm{Si}$ MAS-NMR spectra were obtained using a Bruker MSL-300 spectrometer at $59.63 \mathrm{MHz}, 4 \mathrm{kHz}$ spinning speed, $2 \mu$ s excitation pulses $(\pi / 2$ pulse width of $4 \mu \mathrm{s}$ ) and $80 \mathrm{~s}$ recycle time. The chemical shifts of silicon were referenced to tetramethylsilane (TMS) using a secondary standard of trimethylsilylester of cubic octameric silicate (Q8M8) at $-109.7 \mathrm{ppm}$ (the more shielded signal). ${ }^{27} \mathrm{Al}$ MAS-NMR spectra were obtained using a Bruker MSL-300 spectrometer at 78.21 MHz, $10-12 \mathrm{kHz}$ spinning speed, $0.7 \mu \mathrm{s}$ excitation pulses $(\pi / 2$ pulse width of $9 \mu$ s for an aqueous solution) and $1 \mathrm{~s}$ recycle time. Chemical shifts of aluminium were referenced to a $1 \mathrm{M} \mathrm{Al}\left(\mathrm{NO}_{3}\right)_{3}$ aqueous solution with a chemical shift of $0 \mathrm{ppm} .{ }^{19} \mathrm{~F}$
MAS-NMR spectra were obtained using a Bruker DSX-400 spectrometer at $379.23 \mathrm{MHz}$ with a Hahn echo pulse sequence $(\pi / 2$ pulse $\tau-\pi$ pulse $\tau$-acquisition), $10 \mathrm{kHz}$ spinning speed, $\pi / 2$ pulse width of $7 \mu \mathrm{s}$ and $20 \mathrm{~s}$ recycle time. The value of $\tau$ was synchronized to a rotation period of the spinner $(\tau=100 \mu \mathrm{s})$. Chemical shifts of fluorine were referenced to liquid $\mathrm{CFCl}_{3}$ with a chemical shift of $0 \mathrm{ppm}$. Free Induction Decay (FID) signals were treated after collection following a standard procedure using the software WIN-NMR (Bruker software). The FID signals were smoothed in order to reduce the background noise. Base-line was corrected when necessary.

\section{RESULTS AND DISCUSSION}

\section{Molecular environment of titanium in natural clay materials}

The XANES spectra of the four natural analogue materials and the corresponding enlargement of the pre-edge region are shown in Fig. 2. The features of the main edge are caused mainly by multiple scattering phenomena and therefore are closely linked to the molecular geometry of the Ti atoms (e.g. Ti-O bond length and bond angles). In addition, the pre-edge features indicate electronic excitations probing the characteristics of the molecular bonds formed by Ti. Normalized intensities in combination with the resonance energies of these pre-edge features are closely related to coordinated distortions and oxidation state (Waychunas, 1987; Farges, 1996; Farges et al., 1997).

All samples have similar main edge energies indicating $\mathrm{Ti}$ being present as $\mathrm{Ti}^{4+}$. Furthermore, the mean positions and intensities point towards a common six-fold, octahedral coordination. However, despite the identical $\mathrm{Ti}^{4+}$ oxidation state and octahedral coordination, based on their pre-edge characteristics, the recorded four spectra of the natural Ti-containing clay materials can be divided readily into two groups. Within each group, high spectral similarities are observed. The Ti K-edge XANES obtained for the Rokle and the OPA clay-rock samples are in close agreement with anatase $\left(\mathrm{TiO}_{2}\right.$ with tetragonal crystal symmetry, Ti-O octahedra sharing four edges) (Fig. 2). The pre-edge features and the envelope of the main edge are indicative of crystalline particles. A significant fraction of amorphous or nano-sized $\mathrm{TiO}_{2}$ in the natural materials is excluded due to the absence of an additional characteristic resonance at $4972 \mathrm{eV}$, typical of non-crystalline or nano-crystalline $\mathrm{TiO}_{2}$ 

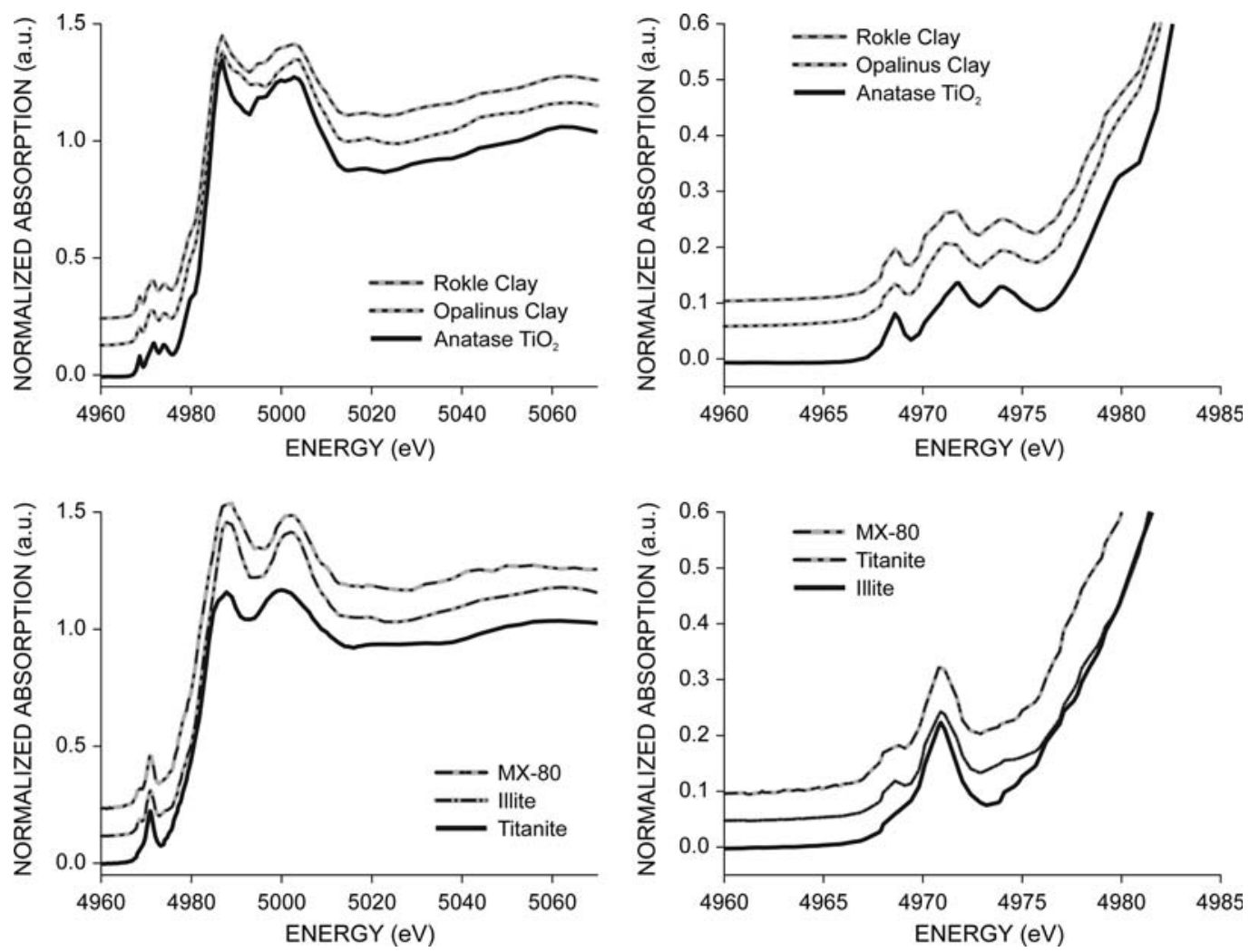

FIG. 2. XANES spectra showing the pre-edge structure of Ti for four natural clays and two reference minerals: (left) complete spectra; (right) close-up of pre-edge spectra.

(Fernandez-Garcia et al., 2007; Flank et al., 2009). The second group, including MX-80 and Illite du Puy, exhibits a strong enhancement of the second pre-edge resonance (at $4971.5 \mathrm{eV}$ ) while the first and third peaks almost disappear. Such an increase in intensity of the central pre-edge feature without a significant shift of its resonance energy can be attributed to an increased distortion of the octahedral coordination of $\mathrm{Ti}$ (Waychunas, 1987; Behrens et al., 1991; Farges, 1996; Jiang et al., 2007). Ti species in MX-80 and Illite du Puy have a similar electronic structure (and similar degree of reduced molecular symmetry) to that of $\mathrm{Ti}$ in titanite, but bond distances deviate as indicated by the difference in the multiple scattering features.

The full EXAFS spectra measured for $\mathrm{Ti}$ in the Rokle and the OPA material are shown in Fig. 3. For comparison, the spectrum of micro-crystalline anatase $\left(\mathrm{TiO}_{2}\right)$ is included also. The close agreement is readily apparent. Accordingly, the predominant molecularlevel coordination of $\mathrm{Ti}$ in these two natural clay-rock

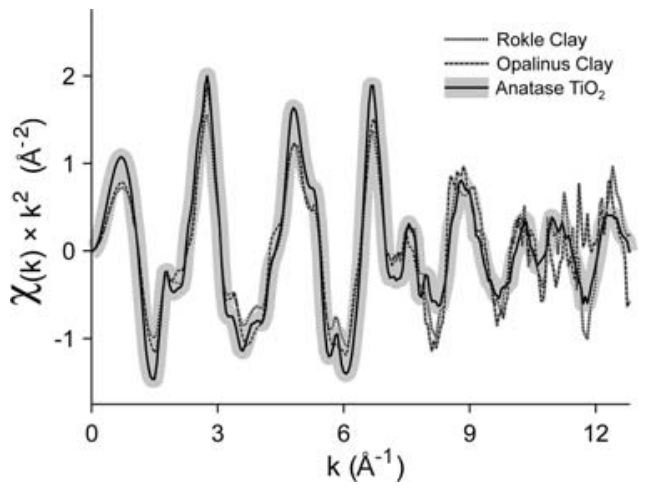

FIG. 3. EXAFS spectra of Rokle bentonite and Opalinus Clay compared with that of micro-crystalline anatase.

materials is in the form of anatase. Compared to the synthetic reference material, only a slight reduction in the EXAFS amplitude is noticed. This observation is consistent with a moderately increased structural 
disorder of the anatase in the natural samples as compared to the synthetic material. Consistent with the pre-edge and XANES analysis discussed previously, the presence of a significant fraction of amorphous $\mathrm{Ti}$ oxide can be excluded. The existence of anatase is further confirmed by synchrotron-based high-resolution powder XRD measurements of the Rokle (Fig. 4) and OPA materials. Anatase is recognized in the XRD pattern despite the pronounced mineralogical complexity. While not as evident, because of the reduced total Ti concentration, there is ample evidence for the presence of anatase in the OPA sample as well (data not shown).

\section{Aging of synthetic montmorillonite and reactions with Ti at $200^{\circ} \mathrm{C}$}

Microscopic morphological observations (SEM). The SEM images of synthetic Na-montmorillonite after synthesis are shown with increasing magnification in Fig. 5a-c. The particles exhibit gypsum-like morphology, similar to that observed for synthetic smectites (Reinholdt et al., 2001). Corresponding images after 1 month of aging are shown in Fig. 5 for treatments under acidic (d), neutral (e) and alkaline conditions (f). The surfaces of the clay particles of the clay material aged under alkaline conditions appear to be scratched, indicating that they may have been affected by the

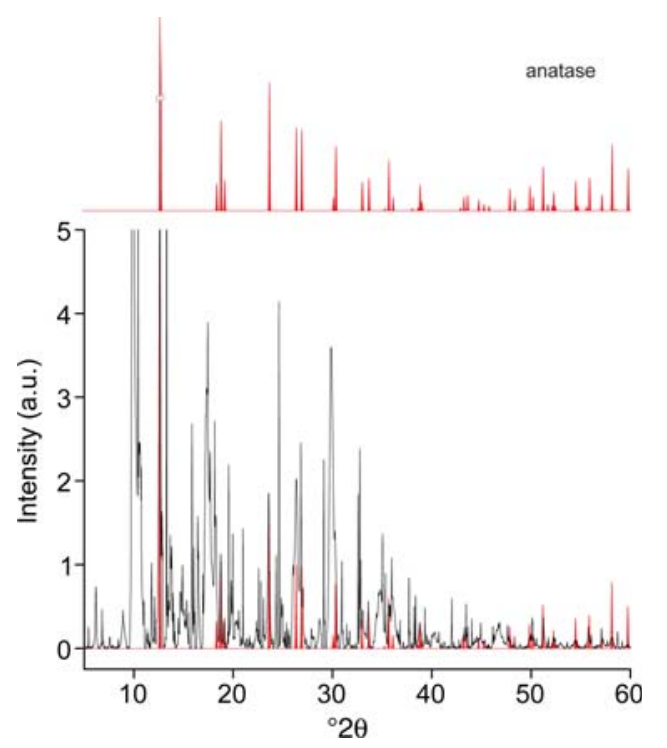

FIG. 4. XRD pattern of Rokle bentonite compared with the anatase pattern. alkaline medium. During aging in the presence of Ti powder for 1 or 4 months, no significant morphological differences compared to the Ti-free system were observed, at any $\mathrm{pH}$. As an example, the synthetic Namontmorillonite reacted for 1 month at neutral $\mathrm{pH}$ is given in Fig. 6a. However, when coarse metallic titanium powder was used as the $\mathrm{Ti}$ source, corresponding micrometre-sized $\mathrm{Ti}$ particles were frequently detected partially covered by smaller clay platelets (Fig. 6b). The EDX analysis allowed the recording of distribution maps of titanium within the synthetic montmorillonite sample (images not shown). The titanium and montmorillonite particles were separated and diffuse distribution of $\mathrm{Ti}$ in the clay particles was not detected. However, with a $\mathrm{Ti}$ detection limit of 10,000 ppm, the SEM-EDX technique is of limited sensitivity. Due to the low corrosion rates of metallic Ti, only trace concentrations of reacted Ti may be expected in the clay material. The presence of Ti particles suggests that the separation method used was not successful, preventing XAS analysis of these samples. In samples for which titanium foils were introduced as the $\mathrm{Ti}$ source, $\mathrm{Ti}$ was not detected by SEM-EDX.

Crystallographic observations (XRD). The XRD (laboratory-based) traces of the original synthetic Na-montmorillonite and after different treatments are shown in Fig. 7. The original synthetic Na-montmorillonite exhibits the expected reflections of the (001), (110; 020), (005), (130; 200), (210), and (060) planes (Reinholdt et al., 2001). The $d_{001}$ value is equal to $15.3 \AA$ (swollen state due to elevated relative humidity) whereas the $d_{060}$ value is equal to $1.49 \AA$, typical of dioctahedral smectites. After aging for 1 month at $200^{\circ} \mathrm{C}$ under neutral conditions, a decrease in the intensity and widening of the (001) reflection was observed which is attributed to a less ordered stacking of the layers. Aging under acidic conditions for 1 month resulted in a slight shift of the (001) reflection towards higher angles (from 5.76 to $5.88^{\circ} 2 \theta$ ). This difference is contrary to what is usually observed for acid-activated natural montmorillonite. However, previous studies on acidactivated montmorillonites showed that activation of various 2:1 type clay minerals at different acid concentrations, reaction times and temperatures led to a broad variety of structural changes (by leaching of structural cations) which depend to a considerable extent on the starting material itself (Komadel et al., 1990; Okada et al., 2006; Bieseki et al., 2013). In the case of alkaline treatment, several modifications were recognized. First, the reflection of the (001) plane was 

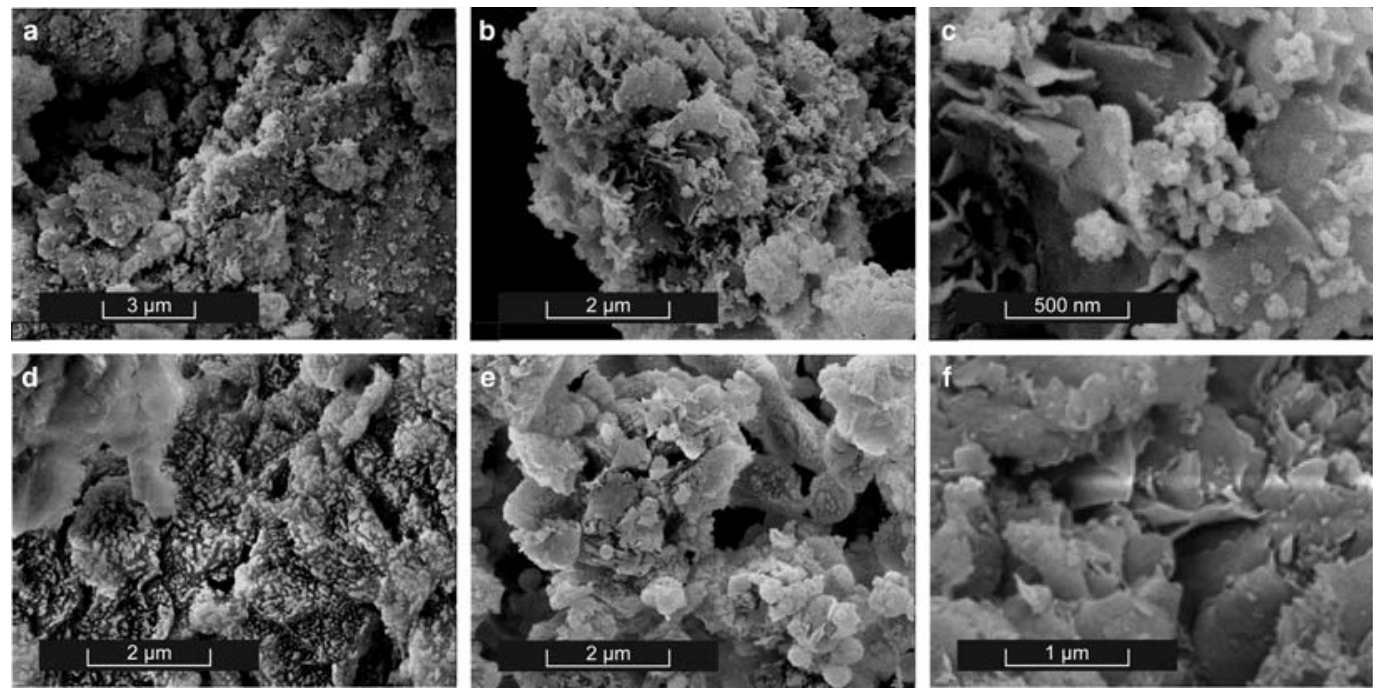

FIG. 5. SEM images of synthetic Na-montmorillonite: $(\mathrm{a}-\mathrm{c})$ unreacted material shown with increasing magnification; (d) aged material after 1 month in acidic conditions; (e) neutral conditions; and (f) alkaline conditions .
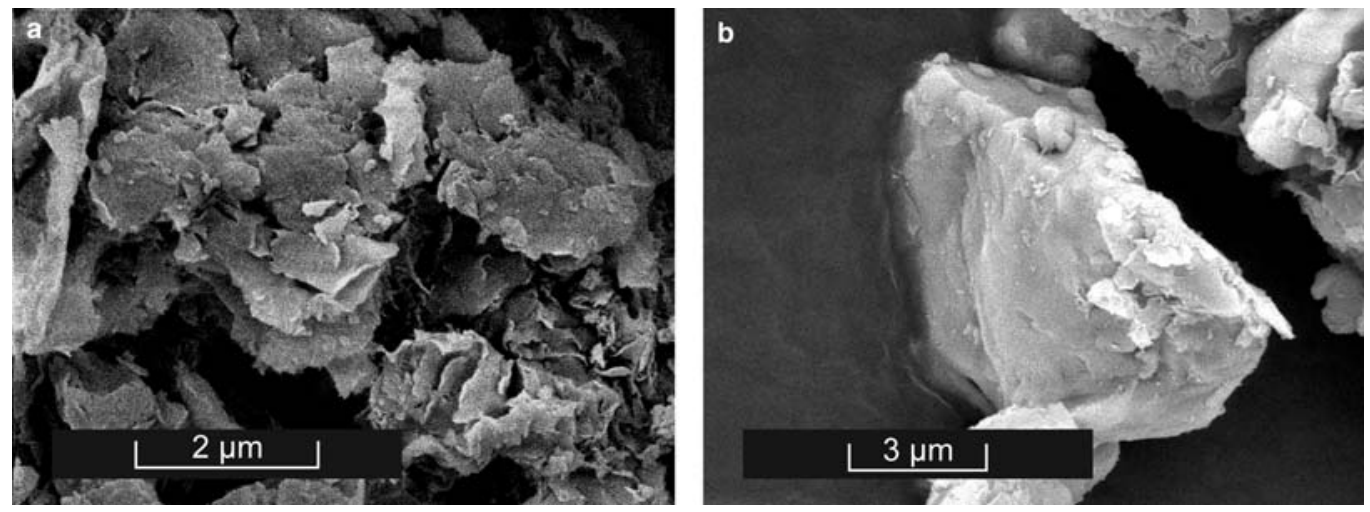

FIG. 6. SEM image of synthetic Na-montmorillonite: (a) reacted for 1 month in neutral conditions in the presence of Ti powder; (b) SEM image of a $\mu \mathrm{m}$-sized Ti particle partially covered by clay platelets.

shifted slightly towards higher angles. In addition, a reduction in the dioctahedral character $\left(d_{060}=1.49 \AA\right)$ and an increase in the trioctahedral one $\left(d_{060}=\right.$ $1.52 \AA$ ) were observed, in agreement with previous studies (Finney et al., 2006; Becerro et al., 2009). The sharp peaks (indicated by arrows in Fig. 7b) are related to the presence of $\mathrm{NaCl}$ which was not fully removed by washing. The hydrothermal treatment clearly does not induce detectable structural modifications at acid or neutral $\mathrm{pH}$. In contrast, aging under alkaline conditions leads to structural changes (e.g. Savage et al., 2002). The nature of these changes will be discussed in greater detail in the context of the solid-state NMR results presented below.

The XRD patterns of the samples after 1 month of treatment in the presence of coarse-grained titanium powder are similar to the Ti-free blank samples (Fig. 7b,c). In line with the detection of Ti particles by SEM, reflections of metallic Ti were observed in the XRD pattern (indicated by arrows in Fig. 7c).

After hydrothermal treatment for 4 months in the presence of titanium foils, the XRD pattern of the synthetic montmorillonite displayed significant differences compared to its original counterpart (Fig. 7d). 


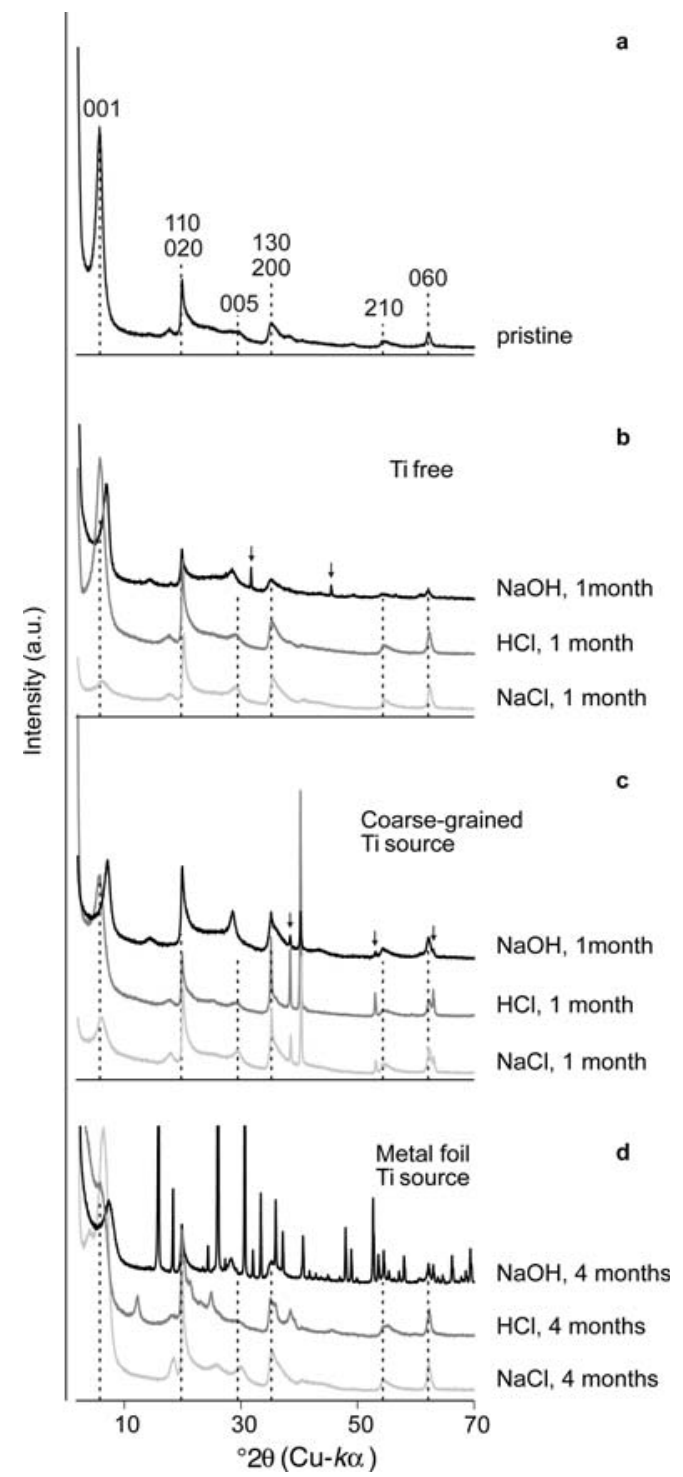

FIG. 7. Comparison of the XRD patterns of synthetic montmorillonite samples aged under different conditions: (a) pristine, non-aged sample; (b) sample aged without $\mathrm{Ti}$ for 1 month at $200^{\circ} \mathrm{C}$; (c) sample aged in the presence of Ti grains for 1 month at $200^{\circ} \mathrm{C}$; (d) sample aged for 1 month at $200^{\circ} \mathrm{C}$ in the presence of Ti foil.

For the sample treated at low $\mathrm{pH}$, a significant decrease of the intensity of the (001) reflection was observed in accordance with previous work on acid-activated smectites (e.g. Okada et al., 2006). Moreover, three broad peaks at $12.3^{\circ}, 24.8^{\circ}$ and $38.5^{\circ} 2 \theta$ appear, indicating the formation of a new, poorly crystalline phase. These three main scattering intensities as well as several additional peaks of lower intensity are congruent with the diffraction pattern of kaolinite. However, the corresponding typical morphology of kaolinite particles could not (yet) be verified in the related SEM images. For the sample reacted at neutral $\mathrm{pH}$, a more pronounced shift of the (001) reflection towards higher angles was observed, corresponding to a decrease in the $d_{001}$ spacing (from $15.3 \AA$ to $13.6 \AA$ ). Moreover, one additional reflection was observed at a low angle (with an associated periodicity of $21.6 \AA$ ). This reflection may be attributed to either the intercalation of one species in the smectite interlayer or to a newly developed ordering with the corresponding periodicity. The first hypothesis can be rejected because, under the pertaining experimental conditions, no large polycations based on $\mathrm{Ti}$ (e.g. as $\left(\left[(\mathrm{TiO})_{8}(\mathrm{OH})_{12}\right]^{4+}\right)$, are expected to form.

The most pronounced changes were observed for the sample treated at high $\mathrm{pH}$ (Fig. 7d). Besides the (hkl) reflections attributed to Na-montmorillonite, the XRD pattern of the sample reacted at high $\mathrm{pH}$ shows a series of narrow peaks corresponding crystalline analcime $\left(\mathrm{NaAlSi}_{2} \mathrm{O}_{6} \cdot \mathrm{H}_{2} \mathrm{O}\right.$ ), a zeolite mineral. The transformation of components of bentonite into zeolite upon alkaline treatment has previously been reported in the literature (Ruiz et al., 1997). The pattern corresponding to analcime is also present in the XRD pattern of the blank Ti-free sample which reacted at the same conditions. The transformations observed were not triggered by $\mathrm{Ti}$, therefore.

Molecular structural observations (NMR). The ${ }^{29} \mathrm{Si}$ MAS NMR spectrum of the synthetic referencemontmorillonite displays resonances corresponding to $\operatorname{Si}(n \mathrm{Al})$ ( $n$ ranges from 0 to 3 ) environments where $n$ represents the number of tetrahedral $\mathrm{Al}$ atoms that are next-nearest neighbours of Si (Fig. 8). The main resonance can be decomposed into two components with chemical shifts at $-94 \mathrm{ppm}$ and $-91 \mathrm{ppm}$. These resonances can be attributed to the presence of $\mathrm{Si}$ (0Al)-type environments in distorted structures (Weiss et al., 1987; Reinholt et al., 2001). The shoulder with a chemical shift at $\delta=-88.6 \mathrm{ppm}$ corresponds to a $\mathrm{Si}$ (1Al) type environment, representing a single $\mathrm{Si}-\mathrm{Al}$ substitution in one of the edge-shared next-nearest tetrahedral sites. The broad resonance centred around $\delta=-110.5 \mathrm{ppm}$ is characteristic of disordered $\left(\mathrm{SiO}_{4}\right)_{n}$ entities and indicates the presence of small amounts of amorphous $\mathrm{SiO}_{4}$ clusters in the system (Reinholdt et al., 2001). 


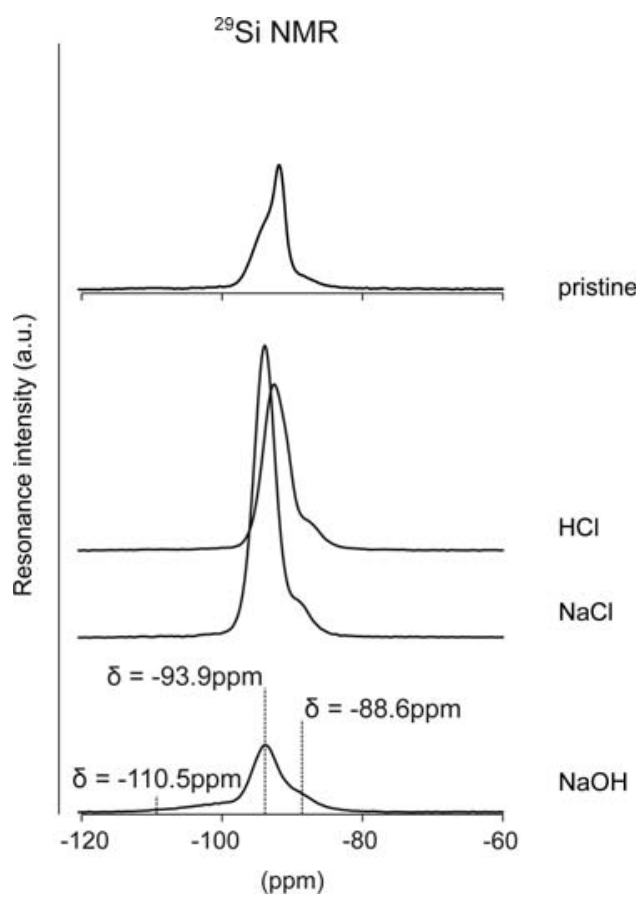

FIG. 8. Decomposition of the ${ }^{29}$ Si MAS NMR spectrum of the pristine synthetic Na-montmorillonite (upper) and the reacted synthetic montmorillonite after 1 month under various conditions.

In the clay material aged for 1 month under neutral and acid conditions, the relative intensities of the two main components at $-94 \mathrm{ppm}$ and $-91 \mathrm{ppm}$ changed noticeably, but the spectra observed are still indicative of the predominance of $\mathrm{Si}(0 \mathrm{Al})$-type environments in distorted structures.

In the clays aged in alkaline solutions, the relative intensity of the resonance at $\sim-110 \mathrm{ppm}$ was enhanced significantly compared to the original synthetic Na-montmorillonite. Similarly, the resonance at $\sim-88.6 \mathrm{ppm}$ was also enhanced. Both observations indicate that the alkaline treatment caused structural modifications. Most important, the increase in tetrahedral aluminium as well as the increase in the amorphous silica content in the sample suggest a partial dissolution of the montmorillonite and the subsequent formation of domains of a new phase. This finding is in line with the observations made by XRD as discussed above. Based on analysis of ${ }^{29} \mathrm{Si} \mathrm{MAS} \mathrm{NMR}$ spectra, the addition of Ti powder or Ti foils did not induce changes in the clay structure measurable by NMR.

The presence of $\mathrm{Al}$ in the octahedral or tetrahedral sheet was determined by ${ }^{27} \mathrm{Al}$ MAS NMR spectroscopy (Fig. 9). For the pristine synthetic montmorillonite, two resonances were observed. The main resonance with a chemical shift at $\sim 5 \mathrm{ppm}$ is attributed to octahedral $\mathrm{Al}\left(\mathrm{Al}^{\mathrm{VI}}\right)$, while the second feature at $\sim 70 \mathrm{ppm}$ is attributed to tetrahedral $\mathrm{Al}$ $\left(\mathrm{Al}^{\mathrm{IV}}\right)$. This result is in accordance with the ${ }^{29} \mathrm{Si}$ MAS NMR data and confirms the Al-for-Si substitutions in the tetrahedral sheet. As expected, the amount of tetrahedral $\mathrm{Al}$ is considerably lower than that of octahedral Al. A comparison between the spectra of the blank samples aged in a $\mathrm{NaCl}$ or $\mathrm{HCl}$ solution and the original synthetic montmorillonite showed no detectable differences. During aging in the $\mathrm{NaOH}$ solution at high $\mathrm{pH}$, however, the amount of tetrahedral $\mathrm{Al}$ was enhanced. Hence, the alkaline treatment seems to affect the proportions of ${ }^{\mathrm{IV}} \mathrm{Al}$ and ${ }^{\mathrm{VI}} \mathrm{Al}$ in line with the evolution of the di- and trioctahedral character established by XRD. A third resonance with a chemical shift at $\delta=57.8 \mathrm{ppm}$ is attributed to ${ }^{\mathrm{IV}} \mathrm{Al}$, but with a different local environment from that observed at $\delta=$ $69.5 \mathrm{ppm}$. Summarizing the ${ }^{27} \mathrm{Al}$ MAS NMR spectroscopy results, structural changes of the montmorillonite at the molecular level could be established. For

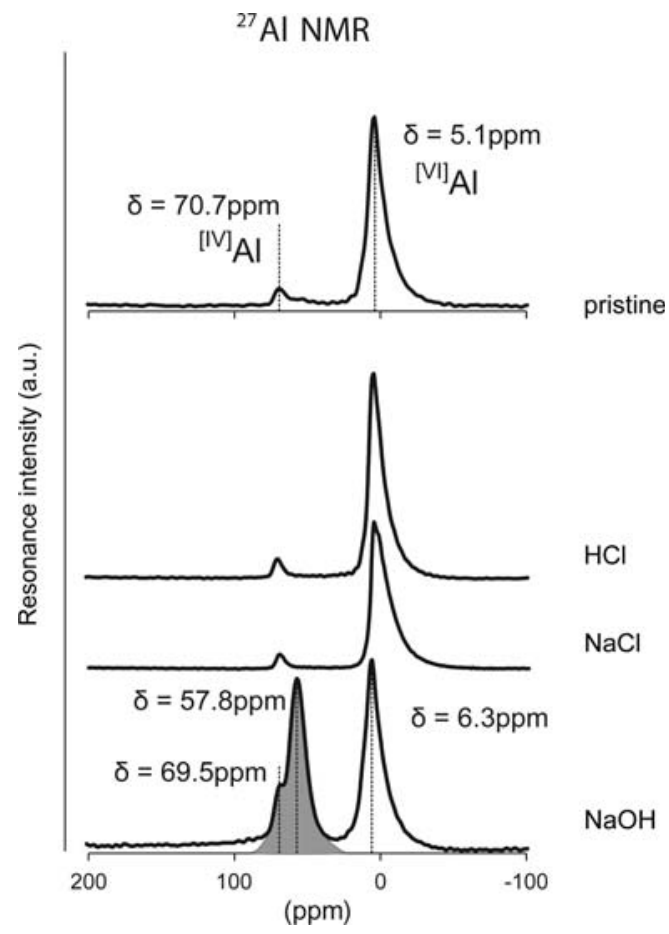

FIG. 9. Al NMR spectra of the pristine synthetic Namontmorillonite (upper) and the reacted synthetic montmorillonite after 1 month under various conditions. 


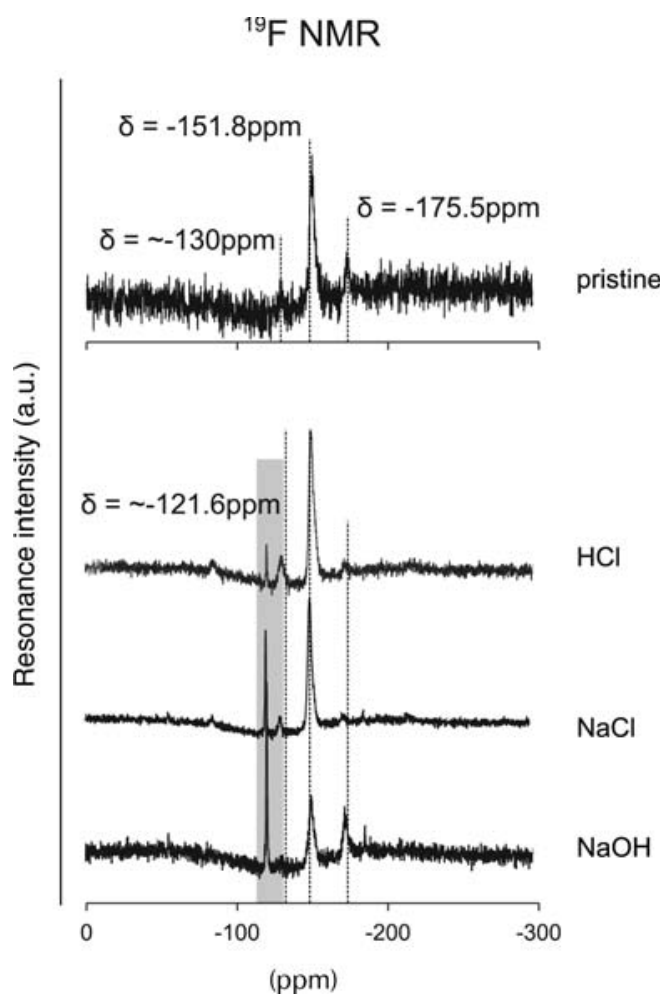

FIG. 10. ${ }^{19} \mathrm{~F}$ NMR spectra of the pristine synthetic Namontmorillonite (upper) and the reacted synthetic montmorillonite after 1 month under various conditions.

all chemical conditions and reaction times employed, the reaction with corrosion products of added titanium sources caused no detectable modifications in the $\mathrm{Al}$ environment.

${ }^{19}$ F MAS NMR spectroscopy is a powerful tool for obtaining information on the octahedral sheet occupancy. The ${ }^{19} \mathrm{~F}$ MAS NMR spectrum of Namontmorillonite displays several peaks with characteristic chemical shifts, each corresponding to a particular fluorine environment (Fig. 10). The main resonance observed with a chemical shift of $\delta=-$ $151.8 \mathrm{ppm}$ is attributed to a Mg-Al- $\square$ environment whereas the two resonances at $\delta=-175.5 \mathrm{ppm}$ and at $\delta$ $=-130.1 \mathrm{ppm}$ are typical of a $\mathrm{Mg}-\mathrm{Mg}-\mathrm{Mg}$ environment and an Al-Al- $\square$ environment, respectively (the $\square$ symbol denotes a vacancy). The samples aged without the addition of $\mathrm{Ti}$ in $\mathrm{NaCl}$ and/or $\mathrm{HCl}$ solution displayed the same basic resonances. However the intensity ratios of the resonances are different. Compared to original synthetic Na-montmorillonite, the $\delta=-175.5 \mathrm{ppm}$ resonance is less pronounced for the aged samples, whereas the resonance at $\delta=-$ $130.1 \mathrm{ppm}$ gained in intensity due to hydrothermal treatment. In addition, in all treated samples, a new resonance appeared at $\delta=-121.6 \mathrm{ppm}$, which may represent an aqueous species due to the release of anionic fluorine into the solution. In the blank samples in $\mathrm{NaOH}$ solution, the resonance at $\delta=-130.6 \mathrm{ppm}$ is less intense than in the neutral and acidic blank samples, and the intensity of the resonance at $175.5 \mathrm{ppm}$ is similar to that at $\delta=-151.8 \mathrm{ppm}$ showing that there is a modification of the fluorine environment.

After contact with $\mathrm{Ti}$ powder or $\mathrm{Ti}$ foils no differences were observed for samples in $\mathrm{NaCl}$ or $\mathrm{HCl}$ solution when compared with the corresponding spectra of Ti-free systems. However, after alkaline treatment, the resonance at $\delta=-121.6 \mathrm{ppm}$ was absent.

The ${ }^{19} \mathrm{~F}$ solid-state NMR investigations revealed that the three treatments have an impact on the fluorine environment. The alkaline treatment influenced the intensity of the different resonances of the spectrum. The $\delta=-121.6 \mathrm{ppm}$ resonance is observed in each blank sample regardless of the reaction treatment.

TABLE 4. $\mathrm{pH}$, electrical conductivity (EC) and chemical composition of the separated solution phase from dismantled $80^{\circ} \mathrm{C}$ Ti-clay interaction samples.

\begin{tabular}{lcccccccccc}
\hline $\begin{array}{l}\text { Sample } \\
\text { number }\end{array}$ & $\begin{array}{c}\mathrm{EC} \\
(\mu \mathrm{S} / \mathrm{cm})\end{array}$ & $\mathrm{pH}$ & $\begin{array}{c}\mathrm{Ti} \\
(\mathrm{mg} / \mathrm{L})\end{array}$ & $\begin{array}{c}\mathrm{Ca} \\
(\mathrm{mg} / \mathrm{L})\end{array}$ & $\begin{array}{c}\mathrm{Mg} \\
(\mathrm{mg} / \mathrm{L})\end{array}$ & $\begin{array}{c}\mathrm{K} \\
(\mathrm{mg} / \mathrm{L})\end{array}$ & $\begin{array}{c}\mathrm{Na} \\
(\mathrm{mg} / \mathrm{L})\end{array}$ & $\begin{array}{c}\mathrm{Al} \\
(\mathrm{mg} / \mathrm{L})\end{array}$ & $\begin{array}{c}\mathrm{Si} \\
(\mathrm{mg} / \mathrm{L})\end{array}$ & $\begin{array}{c}\mathrm{Fe} \\
(\mathrm{mg} / \mathrm{L})\end{array}$ \\
\hline 31 & 1339 & 7.19 & $<20$ & 0.17 & 5.70 & 0.74 & 262 & 0.37 & 71 & $<0.03$ \\
32 & 1352 & 7.36 & $<20$ & 0.16 & 5.68 & 0.87 & 264 & 0.34 & 68 & $<0.03$ \\
33 & 1328 & 7.11 & $<0.01$ & 0.14 & 5.57 & 0.68 & 263 & 0.28 & 73 & $<0.05$ \\
34 & 1334 & 7.22 & $<0.01$ & 0.14 & 5.73 & $<0.5$ & 265 & 0.25 & 70 & $<0.05$ \\
35 & 1324 & 7.32 & $<20$ & 0.18 & 6.09 & 0.83 & 255 & 0.23 & 60 & $<0.03$ \\
36 & 1338 & 7.30 & $<0.01$ & 0.20 & 5.98 & $<0.5$ & 266 & 0.16 & 64 & $<0.05$ \\
\hline
\end{tabular}


However, the corresponding peak disappeared after adding Ti to the solution. This may be attributed to the formation of a complex based on Ti and fluoride, but in order to support this hypothesis, further experiments would have to be carried out.

\section{Ti-clay interactions at $80^{\circ} \mathrm{C}$}

The $\mathrm{pH}$, electrical conductivity (EC) and ICP-AES analysis results of separated solution phases of the dismantled samples are presented in Table 4. In general, the $\mathrm{pH}$ values and $\mathrm{EC}$ values of the samples changed only slightly during the experiments. None of the dismantled samples showed a measurable elevated $\mathrm{Ti}$ level in solution or any other significant changes between samples with or without $\mathrm{Ti}$ in the chemical composition of the separated solution phases. The detection limits varied between sample series, which were analysed on different occasions (after 218 or 602 days of reaction).

The X-ray absorption spectroscopic results detailing the molecular-level environment of Ti after corrosion and subsequent reaction with the synthetic montmorillonite are shown in Fig. 11 (XANES results) and Fig. 12 (EXAFS data). The two samples which differ only in reaction times exhibit distinct but nearly identical pre-edge signatures (Fig. 11, lower). In comparison with reference compounds and natural analogue materials (Fig. 11, upper), the pre-edge signatures of the Ti reacted with the clays indicate an octahedrally coordinated, moderately distorted $\mathrm{Ti}$ site (cf. discussion of Fig. 2). Based on this observation, the formation of nano-crystalline or amorphous ('gellike'), high-symmetry Ti-oxide phases such as anatase and rutile as well as Ti-Fe oxide phases can be ruled out. Further, the Ti substitution in tetrahedral sheets of clay minerals is not compatible with the observed preedge features either.

The EXAFS data (Fig. 12) provide an additional piece of critical information. Despite the trace amount of Ti associated with the clay, EXAFS data of reasonable quality were obtained for two samples, which are in good agreement. Most relevant, the observed oscillatory trace revealed the typical characteristic pattern of multiple interfering waves and consequently indicated more than one dominant scattering pair. This observation is further emphasized by the radial distribution function depicted in the inset of Fig. 12. In addition to a first coordination sphere, two prominent scattering contributors are located at increased distances. The existence of second- or thirdshell contributions at the distances observed, which are typical of molecular bonds, preclude outer-sphere
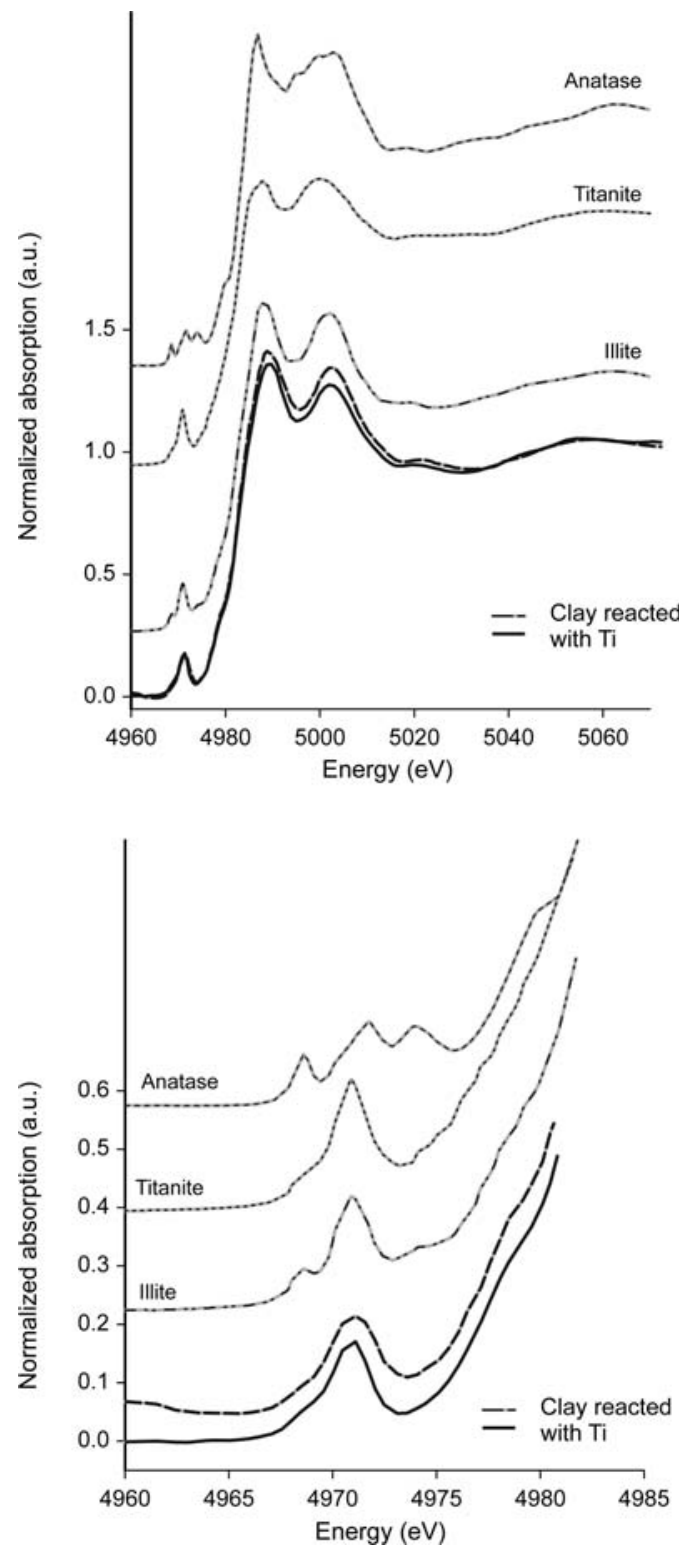

FIG. 11. XANES spectra (Ti pre-edge structure) of synthetic montmorillonite samples reacted with $\mathrm{Ti}$ released from corroding Ti foils. Reaction periods were 218 (solid line) and 601 (dashed line) days at $80^{\circ} \mathrm{C}$ and neutral $\mathrm{pH}$. For comparison additional spectra of reference materials are shown; upper: XANES spectra; lower: closeup of pre-edge spectral region.

sorption being the dominant mode of Ti interaction with the clay. Moreover, the observed magnitude of these higher shell scattering contributions even makes 


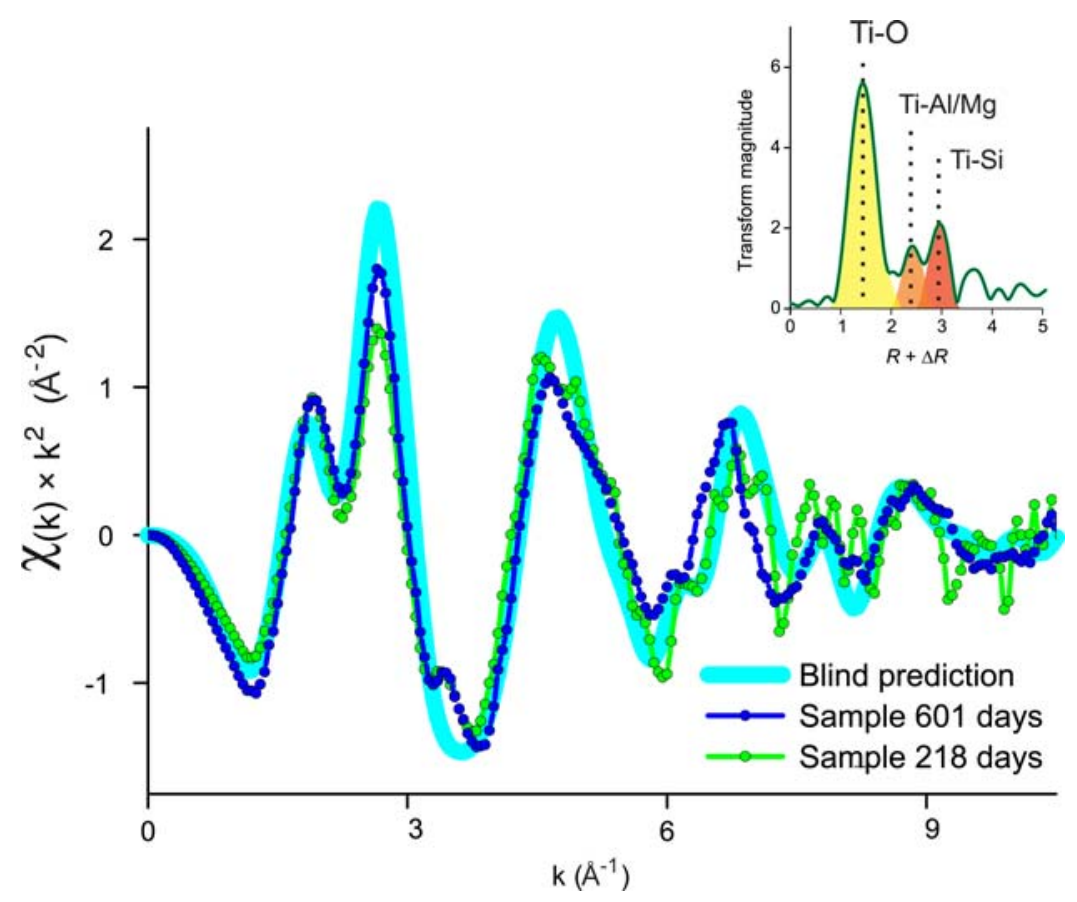

FIG. 12. EXAFS spectra of synthetic montmorillonite samples reacted with Ti released from corroding Ti foils. Reaction periods were 218 and 601 days at $80^{\circ} \mathrm{C}$ and neutral $\mathrm{pH}$. Experimental EXAFS spectra are compared to a spectrum obtained from blind prediction (see text). Inset depicts the radial distribution function.

specific (inner-sphere) sorption to clay-mineral edge sites or planar sites rather unlikely. This leaves the structural incorporation of $\mathrm{Ti}$ into octahedral sites of the smectite as a final plausible reaction mechanism. The corresponding reaction mechanism was introduced as 'neoformation of clays' (Charlet \& Manceau, 1994) based on $\mathrm{Co}(\mathrm{II})$ and $\mathrm{Ni}(\mathrm{II})$ incorporation in clay structures. In addition to a first oxygen shell, two additional scattering contributions are diagnostic of the formation of a phyllosilicate-like local structure. The first is a second shell of nearest metal atoms at $\sim 3.1 \AA$ representing the metal centres of edge-sharing polyhedra in the octahedral sheet. The second is the simultaneous detection of $\mathrm{Si}$ (or substituting cations such as Al) backscatters at $\sim 3.25 \AA$ (Charlet \& Manceau, 1994). Preliminary EXAFS fitting based on these three characteristic scattering pairs yield satisfactory agreement with the experimental data. The mechanism of neoformation of molecular structures similar to those of clay minerals postulated to occur in the present systems is consistent with the finding of structural rearrangements occurring during hydrothermal treatment (at $200^{\circ} \mathrm{C}$ ) as elaborated by XRD and NMR analysis (discussed above). As a further indication, the aqueous solutions of the experiments conducted at $80^{\circ} \mathrm{C}$ contain considerable amounts of $\mathrm{Si}, \mathrm{Al}$ and $\mathrm{Mg}$ documenting the dissolution of initial clay and being available for the neoformation of clays.

In order to further test the hypothesis of neoformation of clay minerals, EXAFS simulations have been conducted, comparing the calculated spectrum of several hypothetical reaction products with the experimental data. The closest match between simulation and experimental data was obtained for Ti incorporated in the octahedral sheet surrounded by $(\mathrm{Al}, \mathrm{Mg})$-centred octahedra and vacancies (Fig. 13). Obviously, due to the large variability of possible combinations of neighbouring polyhedral $\left(\mathrm{Al}^{3+}\right.$-centred, $\mathrm{Mg}^{2+}$-centred or vacancies), no 'unique' molecular geometry can be anticipated. The EXAFS spectra obtained for varying occupancies in the edge-shared polyhedra of the octahedral sheet (but still maintaining the geometrical conformation of a phyllosilicate-like local structure) yield only subtle changes which cannot be refined further based on the quality and range of the 

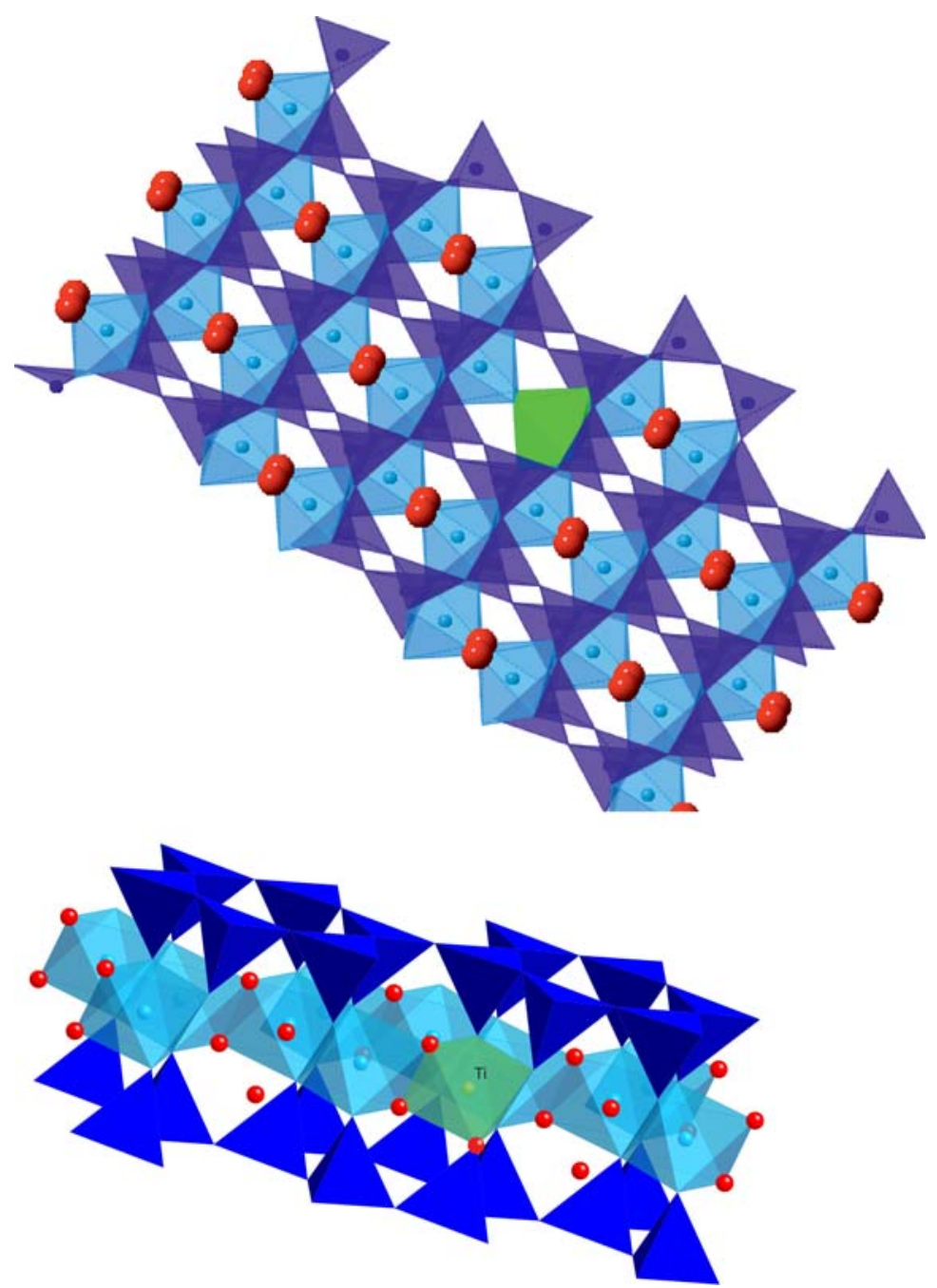

FIG. 13. Molecular sketch of the phyllosilicate structure with Ti incorporated.

experimental EXAFS data available. However, consistent with the previous conclusions, alternative reaction products such as Ti-oxide formation, Ti substituting in the tetrahedral sheet or Ti sorption all result in considerably worse agreement with the experimental spectra.

\section{SUMMARY AND CONCLUSIONS}

The investigation of the interaction of titanium metal with clay minerals at molecular level is of fundamental relevance regarding the geochemical performance of the bentonite buffer in the KBS-3H disposal concept.
The reaction products of Ti-metal corrosion and Ticlay mineral interactions were investigated by a combined wet chemistry and spectroscopic approach.

In a first step, the molecular coordination of $\mathrm{Ti}$ in natural clays was studied by XAS spectroscopy. These data revealed that, in the high-Ti-containing Rokle bentonite and in Opalinus Clay the $\mathrm{Ti}$ occurs predominantly as separate crystalline $\mathrm{TiO}_{2}$ (anatase). In contrast, in the MX- 80 bentonite, which has a much lower $\mathrm{Ti}$ content, Ti occurs in the clay structure, presumably in the octahedral sheet. Hydrothermal aging of synthetic montmorillonite conducted at $200^{\circ} \mathrm{C}$ for up to 4 months with and without titanium showed 
lack or only insignificant changes in the case of nearneutral and acidic conditions. Under alkaline conditions $(\mathrm{pH} \sim 12)$, some alteration was observed, in particular, including formation of trioctahedral clay and the formation of analcime. These changes, however, occurred independently of the addition of Ti. For these samples aged at higher temperatures, XAS analysis was not possible because titanium could not be sufficiently well separated from the clay after the tests.

In the batch tests conducted at $80^{\circ} \mathrm{C}$ for $7-20$ months, successful separation of $\mathrm{Ti}$ from the clay enabled detailed molecular analysis by X-ray absorption spectroscopy. In spite of the small amounts of Ti transferred to the 'Ti-free' synthetic montmorillonite, the nature of Ti could be identified. Thus, the Ti did not occur as separate crystalline or amorphous $\mathrm{TiO}_{2}$ particles. The molecular coordination information obtained by means of modelling of the experimental EXAFS data was consistent with only one unique mechanism: Ti was incorporated in a neo-formed phyllosilicate structure, in a similar manner to that shown previously for $\mathrm{Co}$ and $\mathrm{Ni}$ in smectite (Charlet $\&$ Manceau, 1994). From a practical perspective, the titanium-clay interaction identified should not have adverse consequences on the performance of the buffer. First, the Ti corrosion rate and dissolved $\mathrm{Ti}$ concentrations were low and, second, the Ti released by corrosion reacts with the clay leading to the incorporation of the Ti metal in a neo-formed clay mineral. Thus, the $\mathrm{Ti}$ released by corrosion is actually immobilized. The combination of these two phenomena is expected to lead to restricted diffusion of Ti through the clay. Accordingly, the clay domains exhibiting $\mathrm{Ti}$ enrichment by $\mathrm{Ti}$ incorporation in neo-formed phyllosilicates will correspond to a limited fraction of the entire smectite quantity in the buffer.

In general, the innovative strategy employed, based on the use of synthetic, Ti-free clay material combined with the application of advanced analytical tools (synchrotron-based spectroscopic techniques, solid state NMR), has allowed us to develop an experimentally supported, molecular-level understanding of eventual clay-barrier modifications induced by the corrosive release of Ti.

\section{ACKNOWLEDGEMENTS}

The authors acknowledge Posiva Oy and SKB for providing partial funding to finance this work. The authors thank
Severinne Rigolet for fruitful discussions on NMR results and Sirpa Kumpulainen for laboratory support. The Swiss Light Source at Paul Scherrer Institute, Villigen, Switzerland is acknowledged for provision of synchrotron radiation beamtime at the microXAS beamline.

\section{REFERENCES}

Azumi K. \& Seo M. (2003) Corrosion behavior of titanium-clad carbon steel in weakly alkaline solutions. Corrosion Science, 45, 413-426.

Azumi K., Yasui N. \& Seo M. (2000) Changes in the properties of anodic oxide films formed on titanium during long-term immersion in deaerated neutral solutions. Corrosion Science, 42, 885-896.

Becerro A.I., Mantovani M. \& Escudero A. (2009) Mineralogical stability of phyllosilicates in hyperalkaline fluids: Influence of layer nature, octahedral occupation and presence of tetrahedral Al. American Mineralogist, 94, 1187-1197.

Behrens P., Felsche J., Vetter S., Schulzekloff G., Jaeger N.I. \& Niemann W. (1991) A XANES and EXAFS investigation of titanium silicalite. Journal of the Chemical Society-Chemical Communications, 678-680.

Bieseki L., Treichel H., Araujo A.S. \& Castellã Pergher S. B. (2013) Porous materials obtained by acid treatment processing followed by pillaring of montmorillonite clays. Applied Clay Science, 85, 46-52.

Bradbury M.H. \& Baeyens B. (2009) Sorption modelling on illite part I: Titration measurements and the sorption of Ni, Co, Eu and Sn. Geochimica et Cosmochimica Acta, 73, 990-1003.

Charlet L. \& Manceau A. (1994) Evidence for the neoformation of clays upon sorption of $\mathrm{Co}(\mathrm{II})$ and $\mathrm{Ni}$ (II) on silicates. Geochimica et Cosmochimica Acta, 58, 2577-2582.

Farges F. (1996) Coordination of Ti in crystalline and glassy fresnoites: A high-resolution XANES spectroscopy study at the Ti K-edge. Journal of NonCrystalline Solids, 204, 53-64.

Farges F., Brown G.E. \& Rehr J.J. (1997) Ti K-edge XANES studies of Ti coordination and disorder in oxide compounds: Comparison between theory and experiment. Physical Review B, 56, 1809-1819.

Fernandez-Garcia M., Belver C., Hanson J.C., Wang X. \& Rodriguez J.A. (2007) Anatase- $\mathrm{TiO}_{2}$ nanomaterials: Analysis of key parameters controlling crystallization. Journal of the American Chemical Society, 129, 13604-13612.

Finney W.F., Wilson E., Callender A., Morris M.D. \& Beck L.W. (2006) Reexamination of hexafluorosilicate hydrolysis by $19 \mathrm{~F}$ NMR and $\mathrm{pH}$ measurement. Environmental Science \& Technology, 40, 2572-2577.

Flank A.M., Lagarde P., Itie J.P., Polian A. \& Hearne G.R. (2009) Pressure induced amorphisation and the 
amorphous-amorphous transition in nano-TiO(2): An X-ray absorption spectroscopy study. Pp. 20-24: in Synchrotron Radiation in Materials Science (R.M. Paniago, editor). American Institute of Physics, New York.

Gabis V. (1958) Etude preliminaire des argiles Oligocenes du Puyen-Velay (Haute-Loire) Bulletin de la Société française de Minéralogie et de Cristallographie, 81, 183-185.

Glaus M.A., Frick S., Rosse R. \& Van Loon L.R. (2010) Comparative study of tracer diffusion of $\mathrm{HTO},{ }^{22} \mathrm{Na}^{+}$ and ${ }^{36} \mathrm{Cl}^{-}$in compacted kaolinite, illite and montmorillonite. Geochimica et Cosmochimica Acta, 74, 1999-2010.

Jiang N., Su D. \& Spence J.C.H. (2007) Determination of Ti coordination from pre-edge peaks in Ti K-edge XANES. Physical Review B, 76, 214117.

Karnland O., Olsson S. \& Nilsson U. (2006) Mineralogy and sealing properties of various bentonites and smectite-rich clay materials. SKB TR-06-30, Svensk Kärnbränslehantering $\mathrm{AB}$ (SKB), Stockholm.

King F. (2008) Corrosion of carbon steel under anaerobic conditions in a repository for SF and HLW in Opalinus Clay. NAGRA Technical Report NTB 08-12, Wettingen, Switzerland.

Komadel P., Schmidt D., Madejová J. \& Blahoslav C. (1990) Alteration of smectites by treatments with hydrochloric acid and sodium carbonate solutions. Applied Clay Science, 5, 113-122.

Konta J. (1986) Textural variation and composition of bentonite derived from basaltic ash. Clays and Clay Minerals, 34, 257-265.

Mattsson H. \& Olefjord I. (1984) General corrosion of Ti in hot water and water saturated bentonite clay. Report TR84-19 for SKB (available at http://skb.se/upload/ publications/pdf/TR84-19webb.pdf).

Mattsson H. \& Olefjord I. (1990) Analysis of oxide formed on Ti during exposure in bentonite clay. 1. The oxide growth. Werkstoffe und Korrosion - Materials and Corrosion, 41, 383-390.

Mattsson H., Li C.H. \& Olefjord I. (1990) Analysis of oxide formed on Ti during exposure in bentonite clay. 2. The structure of the oxide. Werkstoffe und Korrosion - Materials and Corrosion, 41, 578-584.

Okada K., Arimitsu N., Kameshima Y., Nakajima A. \& Mackenzie K.J.D (2006) Solid acidity of 2:1 type clay minerals activated by selective leaching. Applied Clay Science, 31, 185-193.

Posiva (2012) Description of KBS-3H design variant. POSIVA 2012-50, 126 pp. ISBN 978-951-652-232-9, Posiva Oy, Eurajoki, Finland.

Posiva (2013) YJH-2012 Nuclear waste management at Olkiluoto and Loviisa power plants: Review of current status and future plans for 2013-2015. Posiva Oy, YJH-2012, Eurajoki, Finland, 363 pp.

Ravel B. \& Newville M. (2005) ATHENA, ARTEMIS, HEPHAESTUS: Data analysis for X-ray absorption spectroscopy using IFEFFIT. Journal of Synchrotron Radiation, 12, 537-541.

Rehr J.J. \& Albers R.C. (2000) Theoretical approaches to $\mathrm{X}$-ray absorption fine structure. Reviews of Modern Physics, 72, 621-654.

Rehr J.J., Albers R.C. \& Zabinsky S.I. (1992) High-order multiple-scattering calculations of X-ray-absorption fine-structure. Physical Review Letters, 69 , 3397-3400.

Rehr J.J., Kas J.J., Prange M.P., Sorini A.P., Takimoto Y. \& Vila F. (2009) Ab initio theory and calculations of X-ray spectra. Comptes Rendus Physique, 10, 548-559.

Reinholdt M., Miehe-Brendlé J., Delmotte L., Tuilier M. H., le Dred R., Cortes R. \& Flank A.M. (2001) Fluorine route synthesis of montmorillonites containing $\mathrm{Mg}$ or $\mathrm{Zn}$ and characterization by XRD, thermal analysis, MAS NMR, and EXAFS spectroscopy. European Journal of Inorganic Chemistry, 2831-2841.

Ruiz R., Blanco C., Pesquera C., Gonzalez F., Benito I. \& Lopez J.L. (1997) Zeolitization of a bentonite and its application to the removal of ammonium ion from waste water. Applied Clay Science, 12, 73-83.

Savage D., Noy D. \& Mihara M. (2002) Modelling the interaction of bentonite with hyperalkaline fluids. Applied Geochemistry, 17, 207-223.

Schutz R.W. (2005) Corrosion of titanium and titanium alloys. Pp. 252-299. in: ASM Handbook, Vol. 13B, Corrosion: Materials (S.D. Cramer and B.S. Covino Jr., editors). ASM International (Materials Park, Ohio, USA).

SKB/POSIVA (2008) Horizontal deposition of canisters for spent nuclear fuel - Summary of the KBS-3H Project 2004-2007. SKB Technical Report TR-08-03. POSIVA 2008-03. Swedish Nuclear Fuel and Waste Management Co (SKB), Stockholm, Sweden and Posiva Oy, Olkiluoto, Finland.

SKB (2011) Long-term safety for the final repository for spent nuclear fuel at Forsmark. SKB Technical Report TR-11-01, Stockholm.

SKB (2012) KBS-3H Complementary Studies 20082010. SKB Technical Report TR-12-01. Swedish Nuclear Fuel and Waste Management Co. (SKB).

Svensson D., Dueck A., Nilsson U., Olsson S., Sandén T., Lydmark S., Jägerwall S., Pedersen K. \& Hansen S. (2011) Alternative buffer material. Status of the ongoing laboratory investigation of reference materials and test package 1. SKB TR-11-06, Svensk Kärnbränslehantering $\mathrm{AB}$ (SKB), Stockholm.

Techer I., Clauer N. \& Liewig N. (2009) Ageing effect on the mineral and chemical composition of Opalinus Clays (Mont Terri, Switzerland) after excavation and surface storage. Applied Geochemistry, 24, 2000-2014.

Thury M. (2002) The characteristics of the Opalinus Clay investigated in the Mont Terri underground rock laboratory in Switzerland. Comptes Rendus Physique, 3, 923-933. 
Thury M. \& Bossart P. (1999) The Mont Terri rock laboratory, a new international research project in a Mesozoic shale formation, in Switzerland. Engineering Geology, 52, 347-359.

Waychunas G.A. (1987) Synchrotron radiation XANES spectroscopy of Ti in minerals - effects of Ti bonding distances, Ti valence, and site geometry on absorptionedge structure. American Mineralogist, 72, 89-101.

Weiss C.A. Jr., Altaner S.P. \& Kirkpatrick R.P. (1987) High spectroscopy of 2:1 layer silicates: correlations among chemical shift, structural distortions and chemical variations. American Mineralogist, 74, 203-215.

Wersin P. \& Birgersson M. (2014) Reactive transport modelling of iron-bentonite interaction within the KBS-3H disposal concept: The Olkiluoto site as a case study. Clays in Natural and Engineered Barriers for Radioactive Waste Confinement, 400, 237-250.
Wersin P., Grolimund D., Kumpulainen S., Kiviranta L., Brendlé J. \& Snellman M. (2010) Titanium alloys as alternative material for the supercontainer shell in the KBS-3H concept. A preliminary Ti-clay interaction study. R-10-51, Svensk Kärnbränslehantering $\mathrm{AB}$ (SKB), Stockholm.

Willmott P.R., Meister D., Leake S.J., Lange M., Bergamaschi A., Böge M., Calvi M., Cancellieri C., Casati N., Cervellino A., Chen Q., David C., Flechsig U., Gozzo F., Henrich B., Jäggi-Spielmann S., Jakob B., Kalichava I., Karvinen P., Krempasky J., Lüdeke A., Lüscher R., Maag S., Quitmann C., Reinle-Schmitt M.L., Schmidt T., Schmitt B., Streun A., Vartiainen I., Vitins M., Wang X. \& Wullschleger R. (2013) The Materials Science beamline upgrade at the Swiss Light Source. Journal of Synchrotron Radiation, 20, 667-682. 